\title{
SELF-MANAGEMENT PADA ANAK EPILEPSI MENGGUNAKAN MOBILE HEALTH APPLICATION: LITERATURE REVIEW
}

\author{
Indah Putri Irdelia ${ }^{*}$, Putri Nilasari $^{2}$ \\ ${ }^{1}$ Mahasiswa Magister Keperawatan Anak, Fakultas Ilmu Keperawatan, Universitas \\ Indonesia \\ ${ }^{2}$ Dasar Keperawatan Keperawatan Dasar, Fakultas Ilmu Keperawatan Universitas \\ Indonesia \\ *email: indah.putri12@ui.ac.id
}

\begin{abstract}
Abstrak
Penyakit kronis neurologis pada anak yang sering ditemukan yaitu epilepsi. Sehingga dibutuhkan sebuah teknologi yang dapat mempermudah penderita epilepsi untuk melakukan self-management. Teknologi yang dapat diterapkan seperti pada pengobatan epilepsi yaitu mobile health application yang digunakan untuk melakukan self-management. Penelitian ini bertujuan untuk mendeskripsikan penggunaan mobile health application untuk self-management pada anak epilepsi. Penelitian ini menggunakan metode Literarature review dari online database UI: Scopus, EBSCOhost, ProQuest, dan Science Direct (20162020) dengan menggunakan kata kunci mobile application, mobile health application, self-management, epilepsy. Hasil pencarian di dapatkan 10 artikel yang dipilih untuk dilakukan telaah dan didapatkan bahwa mobile health application membantu self-management pada anak epilepsi serta meningkatkan kepatuhan pengobatan epilepsi dan membantu penanganan kejang pada anak. Mobile health application memberikan manfaat bagi anak epilepsi dalam melakukan self-management.
\end{abstract}

Kata Kunci : Epilepsi, Mobile Health Application, Self-Management, Anak

\begin{abstract}
The most common chronic neurologic among pediatric is epilepsy. So we need a technology that can be used for epilepsy self-treatment. One of technology that can be used is a mobile health application for self-management. The research purpose to describe mobile health application for self-management in children with epilepsy. This study was used a literature review method from an online database UI: Scopus, EBSCOhost, ProQuest, and Science Direct (2016-2020) using the keywords mobile application, mobile health, self-management, Epilepsy. The search results showed there are 10 articless were selected and to be reviewed and it was found that mobile health application can be used for selfmanagement in children with epilepsy, and also increasing medication adherence, and improves seizure control. Mobile health application provides benefits for children with epilepsy to do self-management.
\end{abstract}

Keywords : Epilepsy, Mobile Health Application, Self-Management, Pediatric

\section{PENDAHULUAN}

Penyakit kronis neurologis pada anak yang sering ditemukan yaitu epilepsi, dimana sekitar 50 juta penduduk dunia mengalami epilepsi (WHO, 2019). Penderita epilepsi $80 \%$ berasal dari negara berkembang (Beghi, 2020). Indonesia sebagai salah satu negara berkembang belum memiliki data yang pasti mengenai insidensi epilepsi hal ini dikarenakan banyaknya penderita epilepsi yang tidak mengunjungi pusat kesehatan dan penderita yang tidak terdeteksi (Kemenkes RI, 2017). World Health Organization (WHO) mengatakan bahwa 4 hingga 10 orang per 1000 mengalami epilepsi, dengan jumlah anak-anak Indonesia per tahun 2020 sebanyak 85.674.305 maka diperkirakan terdapat 342.697 anak di Indonesia mengalami epilepsi (WHO, 2019)(BPS, 2021).

Tujuan utama dalam penatalaksanaan epilepsi adalah untuk 
mengontrol kejang tanpa mengalami efek samping dari medikasi, namun tiga per empat dari penderita epilepsi di negara berkembang tidak mendapatkan pengobatan epilepsi dikarenakan keterbatasan jumlah dokter spesialis saraf dan besarnya biaya pengobatan (Mehndiratta \& Wadhai, 2015). Padahal sangat penting untuk merekam kejadian kejang dan kepatuhan dalam menjalankan pengobatan epilepsi (Choi et al., 2021), sehingga dibutuhkan sebuah teknologi yang dapat mempermudah penderita epilepsi untuk melakukan self-management.

Salah satu teknologi yang sedang berkembang adalah mobile health application. Mobile health application merupakan sebuah perangkat lunak seluler yang berfungsi untuk memantau atau mendeteksi perubahan biologis dalam tubuh manusia, mengumpulkan data kesehatan, dan dapat digunakan untuk perawatan kesehatan sehingga meningkatkan status kesehatan (Park, 2016). Penerapan mobile health application pada pengobatan epilepsi adalah mobile health yang digunakan untuk melakukan self-management. Penggunaan mobile health application meningkatkan kepatuhan pengobatan dan kemampuan self-management penderita epilepsi (Mirpuri et al., 2021). Mobile health application memiliki beberapa fungsi penggunaan yaitu seizure diary, comorbidity self screening, konten edukasi, dan medication reminders (Choi et al., 2021).

Namun saat ini penggunaan mobile health application untuk self-management epilepsi belum diterapkan di Indonesia. Hal ini menunjukan adanya ketinggalan dalam penggunaan teknologi di bidang kesehatan anak di Indonesia. Tujuan literature review ini adalah untuk mendeskripsikan selfmanagement anak dengan epilepsi menggunakan mobile health application.

\section{METODE PENELITAIN}

Metode yang digunakan dalam systematic review ini adalah metode PRISMA untuk mendeskripsikan penggunaan mobile health application untuk self-management pada anak epilepsi

Pencarian jurnal internasional pada penelitian ini dengan mencari jurnal yang relevan sesuai dengan topik melalui database online UI seperti Scopus, ProQuest, EBSCOhost, dan Science Direct. Kata kunci yang digunakan oleh penulis pada proses penelusuran literature adalah mobile application, mobile health application, self-management, Epilepsy.

Penentuan literature pada penelitian ini menggunakan kriteria inklusi dan eklusi yang telah ditetapkan oleh penulis. Kriteria inklusi: penelitian dengan desain cohort study, randomized control trial, cross sectional study, qualitative study, pilot study, dan Prospective study, free full text article, berbahasa inggris, penelitian yang di publikasikan diluar negeri, dipublikasi minimal dalam 5 tahun terakhir (20162021). Kriteria eksklusi: judul dan abstrak tidak sesuai, penelitian telaah jurnal seperti literature/systematic review, penilitian lebih dari 5 tahun terakhir. Proses pemilihan literature dilakukan dengan metode PRISMA, dan dapat dilihat dalam Prisma Flow pada gambar 1 .

\section{HASIL DAN PEMBAHASAN}

Berdasarkan pemaparan dari tabel 1 bahwa 7 dari 10 artikel membahas tentang penggunaan mobile health application untuk self-management pada penderita epilepsi. Serta 3 artikel membahas terkait perspektif orang tua, remaja, serta caregivers terhadap mobile health application untuk self-management pada penderita epilepsi 


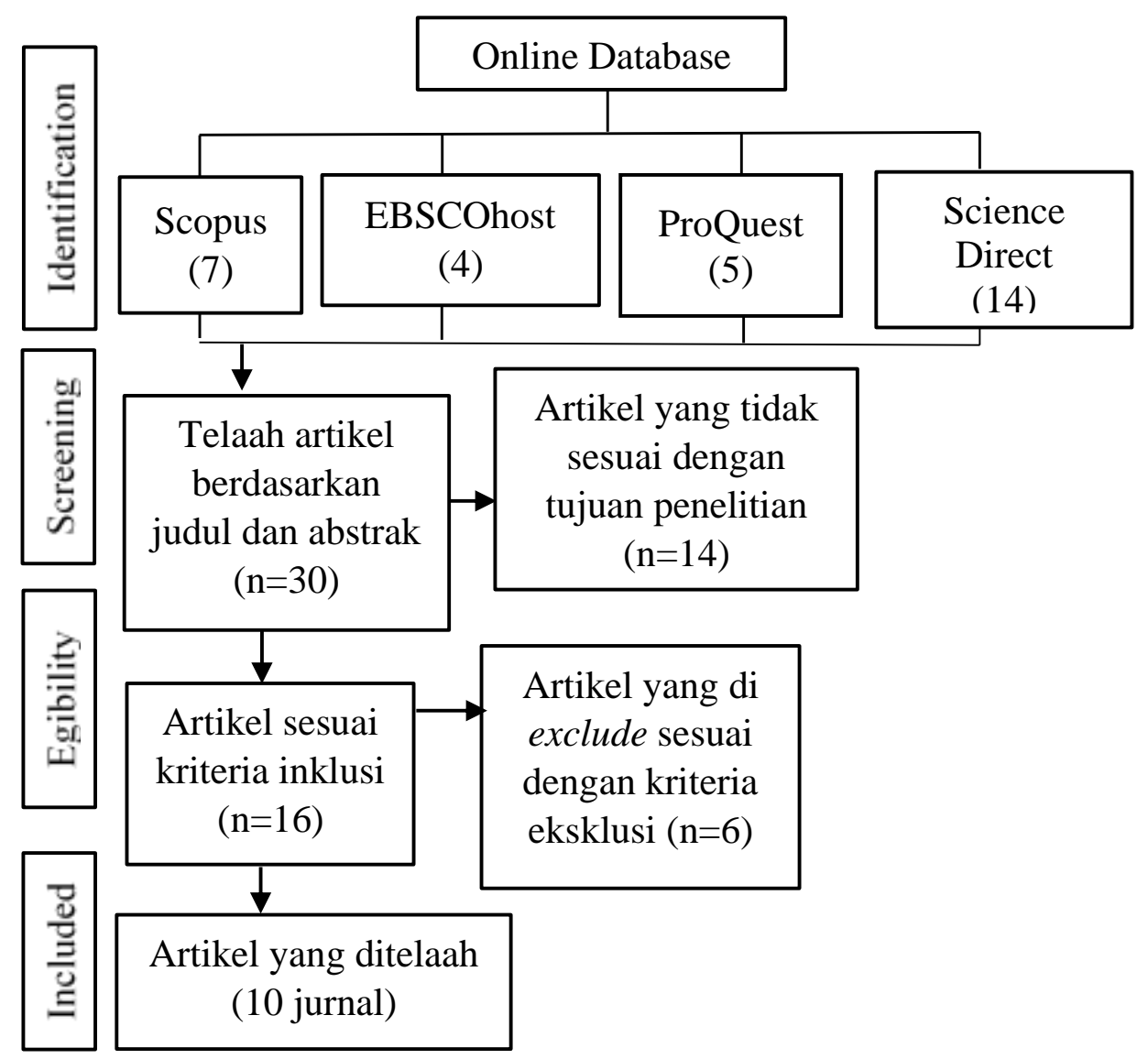

Gambar 1 Prisma Flow

Tabel 1 Rincian Hasil Telaah Systematic Review

\begin{tabular}{|c|c|c|c|c|c|c|c|}
\hline No & $\begin{array}{c}\text { Penulis } \\
\text { dan } \\
\text { (Tahun) }\end{array}$ & Judul & Jurnal & Tujuan & Kategori & Metode & Hasil \\
\hline 1 & $\begin{array}{l}\text { Liu et } \\
\text { al., } \\
\text { (2016) }\end{array}$ & $\begin{array}{l}\text { Smartphone } \\
\text { applications for } \\
\text { seizure care and } \\
\text { management in } \\
\text { children and } \\
\text { adolescents with } \\
\text { epilepsy: } \\
\text { Feasibility and } \\
\text { acceptability } \\
\text { assessment among } \\
\text { caregivers in } \\
\text { China }\end{array}$ & $\begin{array}{l}\text { Epilepsy } \\
\text { Research } \\
127 \\
(2016) 1- \\
5\end{array}$ & $\begin{array}{l}\text { Menentukan } \\
\text { kelayakan serta } \\
\text { sikap antara } \\
\text { caregivers dan } \\
\text { remaja dengan } \\
\text { epilepsi di Cina } \\
\text { terhadap } \\
\text { penggunaan } \\
\text { aplikasi } \\
\text { smartphone } \\
\text { untuk } \\
\text { penanganan } \\
\text { kejang. }\end{array}$ & $\begin{array}{l}\text { Penggunaan } \\
\text { aplikasi }\end{array}$ & $\begin{array}{l}\text { Cross } \\
\text { sectional } \\
\text { study }\end{array}$ & $\begin{array}{l}\text { Penggunaan } \\
\text { aplikasi } \\
\text { smartphone } \\
\text { dalam } \\
\text { penanganan } \\
\text { kejang sangat } \\
\text { membantu } \\
\text { caregivers di } \\
\text { Cina }\end{array}$ \\
\hline
\end{tabular}




\begin{tabular}{|c|c|c|c|c|c|c|c|}
\hline 2 & $\begin{array}{l}\text { Choi et } \\
\text { al., } \\
(2021)\end{array}$ & $\begin{array}{l}\text { Impact of mobile } \\
\text { health application } \\
\text { on data collection } \\
\text { and self } \\
\text { management of } \\
\text { epilepsy }\end{array}$ & $\begin{array}{l}\text { Epilepsy } \\
\& \\
\text { Behavior } \\
119 \\
(2021) \\
107982\end{array}$ & $\begin{array}{l}\text { Mengetahui } \\
\text { penggunaan } \\
\text { mobile } \\
\text { application } \\
\text { dalam } \\
\text { menyediakan } \\
\text { healthcare data } \\
\text { dibandingkan } \\
\text { dengan sistem } \\
\text { konvensional } \\
\text { berdasarkan } \\
\text { data kunjungan } \\
\text { pasien, dan } \\
\text { mengembangka } \\
\text { n self- } \\
\text { management } \\
\text { pada pasien } \\
\text { epilepsy. }\end{array}$ & $\begin{array}{l}\text { Penggunaan } \\
\text { aplikasi }\end{array}$ & $\begin{array}{l}\text { Prospective } \\
\text { study }\end{array}$ & $\begin{array}{l}\text { Mobile health } \\
\text { application } \\
\text { membantu } \\
\text { pasien dan } \\
\text { caregiver untuk } \\
\text { merekam data } \\
\text { perawatan } \\
\text { kesehatan pada } \\
\text { pasien dan } \\
\text { membantu } \\
\text { dalam self- } \\
\text { management } \\
\text { epilepsi. Mobile } \\
\text { health } \\
\text { application } \\
\text { memberikan } \\
\text { validitas klinis } \\
\text { yang } \\
\text { berpengaruh } \\
\text { dalam } \\
\text { perawatan } \\
\text { epilepsi }\end{array}$ \\
\hline 3 & $\begin{array}{l}\text { Le } \\
\text { Marne et } \\
\text { al., } \\
(2018)\end{array}$ & $\begin{array}{l}\text { EpApp: } \\
\text { Development and } \\
\text { evaluation of a } \\
\text { smartphone/tablet } \\
\text { app for } \\
\text { adolescents with } \\
\text { epilepsy }\end{array}$ & $\begin{array}{l}\text { Journal } \\
\text { of } \\
\text { Clinical } \\
\text { Neurosci } \\
\text { ence } 50 \\
(2018) \\
214-220\end{array}$ & $\begin{array}{l}\text { Melakukan } \\
\text { evaluasi secara } \\
\text { komprehensif } \\
\text { terhadap mobile } \\
\text { health } \\
\text { application } \\
\text { (EpApp) yang } \\
\text { dirancang } \\
\text { dengan masukan } \\
\text { dari pemerintah, } \\
\text { untuk } \\
\text { mengedukasi } \\
\text { dan } \\
\text { memfasilitasi } \\
\text { remaja dalam } \\
\text { manajemen } \\
\text { epilepsi. }\end{array}$ & $\begin{array}{l}\text { Penggunaan } \\
\text { aplikasi }\end{array}$ & $\begin{array}{l}\text { Prospective } \\
\text { thort }\end{array}$ & $\begin{array}{l}\text { EpApp mobile } \\
\text { health } \\
\text { application } \\
\text { aplikasi } \\
\text { meningkatkan } \\
\text { pengetahuan } \\
\text { pada penderita } \\
\text { epilepsi untuk } \\
\text { tatalaksana } \\
\text { perawatan } \\
\text { epilepsi. }\end{array}$ \\
\hline 4 & $\begin{array}{l}\text { Si et al., } \\
(2020)\end{array}$ & $\begin{array}{l}\text { Optimising } \\
\text { epilepsy } \\
\text { management with } \\
\text { a smartphone } \\
\text { application: A } \\
\text { randomized } \\
\text { controlled trial }\end{array}$ & $\begin{array}{l}\text { The } \\
\text { Medical } \\
\text { Journal } \\
\text { of } \\
\text { Australia } \\
212 \\
(2020)\end{array}$ & $\begin{array}{l}\text { Menilai } \\
\text { efektivitas } \\
\text { intervensi } \\
\text { berdasarkan } \\
\text { aplikasi } \\
\text { smartphone } \\
\text { untuk } \\
\text { meningkatkan } \\
\text { manajemen diri } \\
\text { dan kontrol } \\
\text { kejang pada } \\
\text { penderita } \\
\text { epilepsi }\end{array}$ & $\begin{array}{l}\text { Penggunaan } \\
\text { aplikasi }\end{array}$ & $\begin{array}{l}\text { Randomized } \\
\text { controlled } \\
\text { trial }\end{array}$ & $\begin{array}{l}\text { Penggunaan } \\
\text { aplikasi khusus } \\
\text { untuk epilepsi di } \\
\text { smartphone } \\
\text { sangat layak dan } \\
\text { efisien, serta } \\
\text { dapat } \\
\text { meningkatkan } \\
\text { Self- } \\
\text { management } \\
\text { pasien, dan } \\
\text { dapat } \\
\text { meningkatkan } \\
\text { kontrol kejang. }\end{array}$ \\
\hline
\end{tabular}




\begin{tabular}{|c|c|c|c|c|c|c|c|}
\hline 5 & $\begin{array}{l}\text { Yoo et } \\
\text { al., } \\
(2020)\end{array}$ & $\begin{array}{l}\text { Developing a } \\
\text { mobile epilepsy } \\
\text { management } \\
\text { application } \\
\text { integrated with an } \\
\text { electronic health } \\
\text { record for } \\
\text { effective seizure } \\
\text { management }\end{array}$ & $\begin{array}{l}\text { Internati } \\
\text { onal } \\
\text { Journal } \\
\text { of } \\
\text { Medical } \\
\text { Informati } \\
\text { cs } 134 \\
(2020) \\
104051\end{array}$ & $\begin{array}{l}\text { Mengembangka } \\
\mathrm{n} \text { mobile } \\
\text { aplikasi pada } \\
\text { penderita } \\
\text { epilepsi yang } \\
\text { mencakup } \\
\text { faktor krusial } \\
\text { secara } \\
\text { komprehensif } \\
\text { dan mudah } \\
\text { untuk digunakan }\end{array}$ & $\begin{array}{l}\text { Penggunaan } \\
\text { aplikasi }\end{array}$ & Pilot study & $\begin{array}{l}\text { Kepuasaan } \\
\text { pasien terhadap } \\
\text { mobile epilepsi } \\
\text { sangat baik }\end{array}$ \\
\hline 6 & $\begin{array}{l}\text { Shegog } \\
\text { et al., } \\
(2020)\end{array}$ & $\begin{array}{l}\text { MINDSET: } \\
\text { Clinic-based } \\
\text { decision support } \\
\text { demonstrates } \\
\text { longitudinal } \\
\text { efficacy for } \\
\text { increased epilepsy } \\
\text { self management } \\
\text { adherence among } \\
\text { Spanish speaking } \\
\text { patients }\end{array}$ & $\begin{array}{l}\text { Epilepsy } \\
\& \\
\text { Behavior } \\
113 \\
(2020) \\
107552\end{array}$ & $\begin{array}{l}\text { Untuk evaluasi } \\
\text { eficasi dari } \\
\text { MINDSET } \\
\text { terhadap } \\
\text { peningkatan self } \\
\text { management } \\
\text { pada hispanis } \\
\text { penderita } \\
\text { epilepsi }\end{array}$ & $\begin{array}{l}\text { Penggunaan } \\
\text { aplikasi }\end{array}$ & $\begin{array}{l}\text { Randomized } \\
\text { controlled } \\
\text { trial }\end{array}$ & $\begin{array}{l}\text { Terjadi } \\
\text { peningkatan } \\
\text { kepatuhan self } \\
\text { management } \\
\text { pada hispanis } \\
\text { penderita } \\
\text { epilepsi dan } \\
\text { mempertahanka } \\
\text { n kepatuhan } \\
\text { secara } \\
\text { longitudinal } \\
\end{array}$ \\
\hline 7 & $\begin{array}{l}\text { Mirpuri } \\
\text { et al., } \\
(2021)\end{array}$ & $\begin{array}{l}\text { The development } \\
\text { and efficacy of a } \\
\text { mobile phone } \\
\text { application to } \\
\text { improve } \\
\text { medication } \\
\text { adherence for } \\
\text { person with } \\
\text { epilepsy in limited } \\
\text { resource settings: } \\
\text { A preliminary } \\
\text { study }\end{array}$ & $\begin{array}{l}\text { Epilepsy } \\
\& \\
\text { Behavior } \\
116 \\
(2021) \\
107794\end{array}$ & $\begin{array}{l}\text { Melakukan } \\
\text { validasi } \\
\text { terhadap mobile } \\
\text { phone aplikasi, } \\
\text { yang } \\
\text { dihipotesiskan } \\
\text { untuk } \\
\text { meningkatkan } \\
\text { kepatuhan } \\
\text { pengobatan dan } \\
\text { kemampuan } \\
\text { self- } \\
\text { management } \\
\text { pada penderita } \\
\text { epilepsi }\end{array}$ & $\begin{array}{l}\text { Penggunaan } \\
\text { aplikasi }\end{array}$ & $\begin{array}{l}\text { Randomized } \\
\text { controlled } \\
\text { Trial }\end{array}$ & $\begin{array}{l}\text { Mobile aplikasi } \\
\text { meningkatkan } \\
\text { kepatuhan } \\
\text { pengobatan dan } \\
\text { kemampuan } \\
\text { self- } \\
\text { management } \\
\text { penderita } \\
\text { epilepsi }\end{array}$ \\
\hline 8 & $\begin{array}{l}\text { Dozières } \\
\text { - } \\
\text { Puyravel } \\
\text { et al., } \\
(2020)\end{array}$ & $\begin{array}{l}\text { Views of } \\
\text { adolescents and } \\
\text { their parents on } \\
\text { mobile apps for } \\
\text { epilepsy self } \\
\text { management }\end{array}$ & $\begin{array}{l}\text { Epilepsy } \\
\& \\
\text { Behavior } \\
106 \\
(2020) \\
107039\end{array}$ & $\begin{array}{l}\text { Memahami } \\
\text { harapan remaja } \\
\text { penderita } \\
\text { epilepsi } \\
\text { serta orang tua } \\
\text { terhadap mobile } \\
\text { aplikasi untuk } \\
\text { self- } \\
\text { management } \\
\text { epilepsi }\end{array}$ & $\begin{array}{l}\text { Perspektif } \\
\text { user }\end{array}$ & $\begin{array}{l}\text { Cross } \\
\text { sectional } \\
\text { study }\end{array}$ & $\begin{array}{l}\text { Remaja } \\
\text { menerima } \\
\text { teknologi baru } \\
\text { pada mobile } \\
\text { health } \\
\text { application } \\
\text { untuk self- } \\
\text { management } \\
\text { epilepsi. } \\
\text { Harapan } \\
\text { tertinggi orang } \\
\text { tua mengenai } \\
\text { mobile aplikasi } \\
\text { adalah } \\
\text { manajemen } \\
\text { kejang dan } \\
\text { informasi } \\
\text { keadaan darurat }\end{array}$ \\
\hline
\end{tabular}




\begin{tabular}{|c|c|c|c|c|c|c|c|}
\hline 9 & $\begin{array}{l}\text { Chiu et } \\
\text { al., } \\
(2021)\end{array}$ & $\begin{array}{l}\text { Seizure action } \\
\text { plans in the } \\
\text { pediatric } \\
\text { population with } \\
\text { epilepsy: Uptake, } \\
\text { determinants, and } \\
\text { parental interest } \\
\text { in a mobile } \\
\text { application } \\
\end{array}$ & $\begin{array}{l}\text { Epilepsy } \\
\& \\
\text { Behavior } \\
117 \\
(2021) \\
107960\end{array}$ & $\begin{array}{l}\text { Menentukan } \\
\text { terapan dari } \\
\text { SAP pada anak, } \\
\text { dan menilai } \\
\text { minat orang tua } \\
\text { terhadap SAP } \\
\text { Mobile } \\
\text { Application }\end{array}$ & $\begin{array}{l}\text { Perspektif } \\
\text { user }\end{array}$ & $\begin{array}{l}\text { Cross } \\
\text { sectional } \\
\text { observationa } \\
\text { l study }\end{array}$ & $\begin{array}{l}\text { Orang tua } \\
\text { tertarik terhadap } \\
\text { aplikasi SAP. } \\
\text { Hanya sebagian } \\
\text { kecil dari } \\
\text { responden yang } \\
\text { menggunakan } \\
\text { SAP }\end{array}$ \\
\hline 10 & $\begin{array}{l}\text { Simblett } \\
\text { et al., } \\
(2019)\end{array}$ & $\begin{array}{l}\text { Patient } \\
\text { perspectives on } \\
\text { the acceptability } \\
\text { of mHealth } \\
\text { technology for } \\
\text { remote } \\
\text { measurement and } \\
\text { management of } \\
\text { epilepsy: A } \\
\text { qualitative study }\end{array}$ & $\begin{array}{l}\text { Epilepsy } \\
\& \\
\text { Behavior } \\
97 \\
(2019) \\
123-129\end{array}$ & $\begin{array}{l}\text { Melakukan } \\
\text { pendalaman } \\
\text { analisis } \\
\text { kualitatif } \\
\text { tentang persepsi } \\
\text { penderita } \\
\text { epilepsi yang } \\
\text { tidak terkontrol } \\
\text { sebagai potensi } \\
\text { penggunaan } \\
\text { mHealth } \\
\text { teknologi dan } \\
\text { untuk } \\
\text { mengidentifikas } \\
\text { i potensi } \\
\text { hambatan dan } \\
\text { fasilitator awal } \\
\text { untuk } \\
\text { keterlibatan di } \\
\text { tiga negara } \\
\text { Eropa }\end{array}$ & $\begin{array}{l}\text { Perspektif } \\
\text { user }\end{array}$ & $\begin{array}{l}\text { Qualitative } \\
\text { study }\end{array}$ & $\begin{array}{l}\text { Partisipan } \\
\text { tertarik pada } \\
\text { teknologi } \\
\text { kesehatan } \\
\text { sebagai alat } \\
\text { deteksi klinis. } \\
\text { Hambatan } \\
\text { utama dalam } \\
\text { penggunaan } \\
\text { mHealth adalah } \\
\text { potensi } \\
\text { peningkatan } \\
\text { stigma dan } \\
\text { kecemasan }\end{array}$ \\
\hline
\end{tabular}

Hasil dari telaah sepuluh sumber yang telah ditemukan, didapatkan bahwa 7 dari 10 artikel membahas mengenai penggunaan mobile health application untuk self-management anak epilepsi. Dari berbagai hasil literature tersebut didapatkan bahwa penggunaan mobile health application sangat membantu dalam selfmanagement pada anak epilepsi. Mobile health application untuk self-management pada anak epilepsi salah satunya yaitu Brain4U, terdiri dari beberapa fitur seperti seizure diary, medication reminders, comorbidity self screening, konten edukasi serta aplikasi ini terintegrasi dengan electronic health record (EHR) di rumah sakit (Yoo et al., 2020) (Choi et al., 2021).

Aplikasi Brain4U yang didesain oleh Yoo et al., (2020) mendapatkan kepuasan yang baik dari pengguna aplikasi. Hasil penelitian ini membantu pasien dan caregiver untuk merekam data perawatan kesehatan pasien dan membantu dalam selfmanagement epilepsi serta meningkatkan kepatuhan pengobatan pasien epilepsi (Choi et al., 2021). Penelitian ini sejalan dengan penelitian Mirpuri et al., (2021) penggunaan mobile aplikasi meningkakan self-management pada penderita epilepsi. Namun hal ini bertolak belakang dengan penelitian yang dilakukan Le Marne et al., (2018) tidak ada peningkatan yang signifikan terhadap self efficacy penderita epilepsi.

Penelitian lain yang dilakukan oleh Le Marne et al., (2018) dengan menggunakan aplikasi EpApp. Aplikasi ini terdiri dari fitur epilepsy profile's, seizure diary, personalized seizure statistics, edukasi, dan medications reminder dimana anak dengan epilepsi dan orang diminta untuk menggunakan aplikasi EpApp. Hasil menunjukan EpApp membantu meningkatkan pengetahuan pada penderita epilepsi untuk tatalaksana perawatan epilepsi, namun tidak ada peningkatan 
signifikan terhadap seizure burden dan parameter psikososial.

Shegog et al., (2020) melakukan penelitian dengan menggunakan aplikasi MINDSET (Management Information and Decision Support Epilepsy Tool) pada hispanis penderita epilepsi. MINDSET merupakan program aplikasi pada tablet yang didesain untuk membantu penderita epilepsi melakukan self-management. MINDSET terdiri dari beberapa fitur untuk menilai kejang pada pasien, medikasi, lifestyle, keselamatan pasien, dan informasi manajemen perilaku. Hasil penelitian didapatkan bahwa penggunaan MINDSET meningkatan kepatuhan self-management pada hispanis penderita epilepsi dan mempertahankan kepatuhan secara longitudinal. Hasil penelitian Shegog et al., (2020) didukung oleh hasil penelitian yang dilakukan $\mathrm{Si}$ et al., (2020) bahwa penggunaan mobile health application untuk epilepsi sangat efisien dan layak, serta meningkatkan self-management pasien. Manfaat penggunaan mobile health application untuk self-management epilepsi, tidak hanya dirasakan oleh penderita epilepsi tetapi juga berdampak pada caregivers.

Penelitian yang dilakukan Liu et al., (2016), kepada caregivers di Cina yang merawat anak dengan epilepsi didapatkan data bahwa dengan penggunaan aplikasi smartphone dalam penanganan kejang sangat membantu caregivers, dan caregivers sangat tertarik dalam penggunaan aplikasi untuk penatalaksanaan epilepsi. Hal ini sejalan dengan penelitian Chiu et al., (2021) dan Dozières-Puyravel et al., (2020) terhadap respon orang tua pada aplikasi self-management epilepsi, orang tua dari anak epilepsi sangat tertarik dan memiliki antusias yang tinggi terhadap penggunaan aplikasi ini. Namun dalam penggunaan aplikasi terdapat kecemasan orang tua akan adanya stigma kepada anak, biaya yang tinggi, serta kecemasan dalam penggunaan device (Simblett et al., 2019). SIMPULAN
Salah satu teknologi yang sedang berkembang adalah mobile health application. Penerapan mobile application pada pengobatan epilepsi adalah mobile health application yang digunakan untuk melakukan self-management. Penggunaan mobile health application meningkatkan kepatuhan pengobatan dan kemampuan self-management penderita epilepsi.

Literature review yang dilakukan pada mobile health application untuk selfmanagement pada anak epilepsi, menunjukan bahwa penggunaan mobile health application seperti Brain4U, MINDSET, dan EppApp membantu dalam melakukan self-management pada anak epilepsi. Didapatkan hasil bahwa penggunaan mobile health application ini meningkatkan kepatuhan pengobatan pada pasien, membantu dalam kontrol kejang, serta meningkatkan pengetahuan pasien dan caregiver tentang epilepsi.

Penggunaan mobile health application untuk self-management pada anak epilepsi mendapatkan antusias dan kepuasaan dari caregivers, orangtua, dan anak. Namun dalam penggunaannya perlu dikaji kembali terkait legal aspek, etika keperawatan, proses asuhan keperawatan, serta terapeutik komunikasi yang digunakan pada aplikasi. Diharapkan penggunaan mobile health application ini dapat diterapkan di Indonesia, agar dapat memudahkan perawat dalam menentukan asuhan keperawatan terbaik kepada anak, memonitor status kejang pada anak, dan kepatuhan pengobatan. Serta menjadi menjadi sarana komunikasi yang efektif antara perawat dan pasien.

\section{UCAPAN TERIMA KASIH}

Ucapan terimakasih peneliti kepada Fakultas Ilmu Keperawatan Universitas Indonesia dan dosen pembimbing Ns. Putri Nilasari, S.Kep., M.Kep dalam pembuatan systematic review ini. 


\section{DAFTAR PUSTAKA}

Beghi, E. (2020). The Epidemiology of Epilepsy. Neuroepidemiology, 54(2), 185-191. https://doi.org/10.1159/000503831

BPS. (2021). Hasil sensus penduduk 2020. https://www.bps.go.id/pressrelease/20 21/01/21/1854/hasil-sensuspenduduk-2020.html

Chiu, M., Peinhof, S., De Guzman, C., Borhani, M., Siu, C., Kuzeljevic, B., Schrader, D., Huh, L., \& Connolly, M. B. (2021). Seizure action plans in the pediatric population with epilepsy: Uptake, determinants, and parental interest in a mobile application. Epilepsy \& Behavior, 117, 107860. https://doi.org/10.1016/J.YEBEH.202 1.107860

Choi, S. A., Lim, K., Baek, H., Yoo, S., Cho, A., Kim, H., Hwang, H., \& Kim, K. J. (2021). Impact of mobile health application on data collection and self-management of epilepsy. Epilepsy \& Behavior, 119, 107982. https://doi.org/10.1016/J.YEBEH.202 1.107982

Dozières-Puyravel, B., Danse, M., Goujon, E., Höhn, S., \& Auvin, S. (2020). Views of adolescents and their parents on mobile apps for epilepsy selfmanagement. Epilepsy \& Behavior, 106, 107039.

https://doi.org/10.1016/J.YEBEH.202 0.107039

Kemenkes RI. (2017). Keputusan menteri kesehatan Republik Indonesia Nomor HK. 01.07/Menkes?367/2017 tentang pedoman nasional pelayanan kedokteran tata laksana epilepsi pada anak. 1-23.

Le Marne, F. A., Butler, S., Beavis, E., Gill, D., \& Bye, A. M. E. (2018). EpApp: Development and evaluation of a smartphone/tablet app for adolescents with epilepsy. Journal of Clinical Neuroscience, 50, 214-220. https://doi.org/10.1016/J.JOCN.2018. 01.065

Liu, X., Wang, R., Zhou, D., \& Hong, Z.
(2016). Smartphone applications for seizure care and management in children and adolescents with epilepsy: Feasibility and acceptability assessment among caregivers in China. Epilepsy Research, 127, 1-5. https://doi.org/10.1016/J.EPLEPSYR ES.2016.08.002

Mehndiratta, M. M., \& Wadhai, S. A. (2015). International Epilepsy Day A day notified for global public education \& awareness. The Indian Journal of Medical Research, 141(2), 143. /pmc/articles/PMC4418146/ Mirpuri, P., Chandra, P. P., Samala, R., Agarwal, M., Doddamani, R., Kaur, K., Ramanujan, B., Chandra, P. S., \& Tripathi, M. (2021). The development and efficacy of a mobile phone application to improve medication adherence for persons with epilepsy in limited resource settings: A preliminary study. Epilepsy \& Behavior, 116, 107794. https://doi.org/10.1016/J.YEBEH.202 1.107794

Park, Y.-T. (2016). Emerging New Era of Mobile Health Technologies.

Healthcare Informatics Research, 22(4), 253.

https://doi.org/10.4258/HIR.2016.22.4 .253

Shegog, R., Braverman, L., \& Hixson, J. D. (2020). Digital and technological opportunities in epilepsy: Toward a digital ecosystem for enhanced epilepsy management. Epilepsy \& Behavior, 102, 106663. https://doi.org/10.1016/J.YEBEH.201 9.106663

Si, Y., Xiao, X., Xia, C., \& Guo, J. (2020). Optimising epilepsy management with a smartphone application: a randomised controlled trial. https://remotelib.ui.ac.id:2120/record/display.uri?ei $\mathrm{d}=2$-s 2.0 $85082192396 \&$ origin $=$ resultslist\&sort $=$ plf-

$\mathrm{f} \& \mathrm{src}=\mathrm{s} \& \mathrm{sid}=\mathrm{f} 34 \mathrm{a} 1825 \mathrm{f} 4428 \mathrm{f} 3452 \mathrm{bb}$ 
17f4df7ae50e\&sot $=b \& s d t=b \& s l=62 \& s=T I$ TLE-ABS-

KEY\%28mobile+application+for+self + management+epilepsy\%29\&relpos= $10 \&$ citeCnt $=6 \&$

Simblett, S. K., Bruno, E., Siddi, S., Matcham, F., Giuliano, L., López, J. H., Biondi, A., Curtis, H., Ferrão, J., Polhemus, A., Zappia, M., Callen, A., Gamble, P., \& Wykes, T. (2019).

Patient perspectives on the acceptability of mHealth technology for remote measurement and management of epilepsy: A qualitative analysis. Epilepsy \& Behavior, 97, 123-129.
https://doi.org/10.1016/J.YEBEH.201 9.05.035

WHO. (2019). Epilepsy. https://www.who.int/news-room/factsheets/detail/epilepsy

Yoo, S., Lim, K., Baek, H., Jang, S. K., Hwang, G. young, Kim, H., \& Hwang, H. (2020). Developing a mobile epilepsy management application integrated with an electronic health record for effective seizure management. International Journal of Medical Informatics, 134, 104051.

https://doi.org/10.1016/J.IJMEDINF.2 019.104051 